\title{
Gamification Teaching Reform for Higher Vocational Education in China: A Case Study on Layout and Management of Distribution Center
}

\author{
https://doi.org/10.3991/ijet.v12.i09.7493 \\ Fan Wang( $\left.{ }^{\bowtie}\right)$, Yanli Wang, Xia Hu \\ Shijiazhuang Posts and Telecommunications Technical College, Shijiazhuang, Hebei, China \\ coolbased $163 . \mathrm{com}$
}

\begin{abstract}
Currently, students in higher vocational schools in China are passive in classrooms and depend too much on cellular phones. Thus, structural readjustment of the teaching organization is urgently needed. Increasing proportions of gamifying teaching and experiencing teaching is an effective way to solve this problem. However, only a few studies have discussed the gamification of teaching reform in colleges. To improve the effectiveness of teaching and increase the participation of students in classrooms, the teaching reform idea and scheme of gamifying teaching and experiencing teaching were discussed in a course entitled Layout and Management of Distribution Center. The teaching reform aims to integrate comprehensive gamifying into the teaching of an entire curriculum. Specifically, small games are designed in each class during the early period to help the students learn the corresponding knowledge in games. A game-driven model of curriculum design was proposed and applied in teaching reform practice of Shijiazhuang Posts and Telecommunications Technical College. Results demonstrated that gamification of teaching reform achieves outstanding effects. Students participate in classroom activities positively, and all evaluation indexes improve year by year. Results confirm that teachers need to pay attention to systemization, gamification, and immersion of teaching design, and ensure the attractiveness and acceptability of the teaching method.
\end{abstract}

Keywords - gamification, sand table teaching, experiencing teaching, teaching reform

\section{Introduction}

Nowadays, higher vocational education in China is facing serious structural problems, such as a high proportion of theoretical courses, difficulty of textbooks, emphasis on knowledge memory but neglecting comprehension of knowledge, emphasis on operation but neglecting thinking in practical terms, and absence of practical project support in course construction. Adjusting curriculum structure, increasing the proportion of gamifying and experiencing teaching, and helping students accept and even explore knowledge positively through games are important.

Recently, gamification is becoming increasingly popular and is widely used in various settings, such as education, industry, commerce, environment, government, and 
marketing [1]. Gamification may increase the participation and entertainment of users. Therefore, the academic and practice circles view gamification as a new method to reform the traditional teaching mode [2-4]. Gamification has been used in primary school, middle school, university education, and some training courses. It even appears in new education modes such as the flipped classroom [5].

In this study, the idea and scheme of gamifying and experiencing teaching were introduced based on the Layout and Management of Distribution Center for logistics majors. The implementation details of teaching reform at the supply side were described from microscopic levels, including curriculum design, teaching organization, and teaching method.

\section{State of art}

\subsection{Experiencing teaching}

The theoretical basis of experiencing teaching dates back to the early twentieth century. Dewey, an educator, proposed the teaching idea of "learning by doing" and advocated the full use of children's game ability in teaching and learning knowledge through activities [6]. In 1982, Daniel Conrad published a paper entitled "The Impact of Experimental Education on Adolescent Development," where he summarized the findings of a national study of 27 various programs and concluded that experiencebased educational programs can have a significantly positive impact on the social, psychological, and intellectual development of adolescents [7]. Knapp further emphasized the importance of individual experience, introducing the development of outdoor exercise activities and similar educational institutions [8]. David A. Kolb proposed experiential learning theory after his constant pursuit and exploration of related issues throughout his 50-year academic career [9].

In China, studies on experiencing teaching started in the 1990s. An increasing number of studies have focused on the practice of experiencing teaching. Many scholars have explored practices by combining specific courses. However, they focus on qualitative studies, and research that combines theory and practice is lacking [10].

\subsection{Gamification}

Various definitions of gamification have been presented in the literature. Deterding defined gamification as "using gamified design elements in non-game scenarios" [11]. Kapp believed that gamification-based learning mainly attracts others, encourages behaviors and solves problems [12]. On this basis, Sun Kai deemed that gamification in the field of education aims to "attract others, encourage and promote learning effect, and solve problems through gamification mechanism, aesthetics and gamification means" [13].

Gamifying teaching can increase the potential of learning motivations and participation, thus enabling teachers to guide and reward students better, and significantly improving the cognition, emotional, and social skills of students [14]. In gamification- 
based learning, learners do not plan one game only throughout the whole class. Instead, game elements (e.g., points, passing tests, medals, and high scores) are integrated into the curriculum [15-16]. In foreign countries, educational games serve as supporting tools for individual learning and can arouse the learning enthusiasm of students. Nevertheless, some issues exist with regard to how games can be integrated in classroom teaching.

Domestic studies on gamifying teaching mainly focus on kindergartens and primary schools. Researchers on gamifying teaching in higher education and adult education mainly concentrate on sports, language, and computer classes. Associated studies introduced implementation details of gamifying teaching. Such studies have great limitations in classroom games and offer few references to other courses. Chinese academic studies on educational games mainly concentrate on the development of educational games and are mainly review studies, studies of basic theory, studies of technological design and development, and studies of disciplinary applications. Only a few experimental and quasi-experimental studies exist, thereby resulting in associated data shortage.

A literature review on gamifying teaching in recent decades shows that some limitations still exist, although gamifying learning has achieved some theoretical and practical references. First, only a few theoretical and practice studies combine education and entertainment. Second, hardly any reasonable and effective evaluation methods on gamifying teaching exist. Third, numerous studies and practices on gamifying teaching design in one course module exist, but almost none discussed the overall task design on the basis of the advantages of gamification-based learning.

To address the abovementioned teaching problems, this study proposed to integrate gamifying thinking in teaching a whole course. A comprehensive project entitled "sand table exercise of distribution center operations management" was used as the principal line of gamification design and background to design games according to specific knowledge points. Designed tasks were explained and performed gradually until the task was finally accomplished. A game was designed for each class to attract the attention of the students and help the students think and master the relevant knowledge in the games. The effect of gamifying teaching was evaluated by combining the practical situation of the curriculum.

The remainder of this study is organized as follows: Section 3 introduces the theoretical basis, presents the reform principle of gamifying teaching, describes gamifying teaching programs and corresponding classroom games, and offers a detailed introduction of some classroom games. Section 4 illustrates the teaching effect of gamifying teaching. Section 5 concludes this study.

\section{$3 \quad$ Methodology}

\subsection{Theoretical basis}

Each teaching mode has a corresponding theoretical basis, which is either public theoretical basis or special theoretical basis. A review of articles published since 1997 
showed that most scholars agreed on the theoretical basis of experiencing learning, including constructivism teaching theory, modern teaching concept, cognitive teaching theory, and Bruner's discovery learning theory.

With regard to gamifying teaching, the theory of master learning proposed by James H. Block pointed out that most students are willing to participate in gamification-based learning activities, and through such activities, teachers can actually help students learn faster and better [17]. Advances in cognitive neuroscience facilitated the exploration of the brain learning mechanism and provided important support to the research and design of gamification-based learning [18].

Guided by these theories, curriculum reform has experienced two years of exploration, and the supported sand table for teaching was designed. In this background, early teaching contents were organized and designed based on games.

\subsection{Reform principle of gamifying teaching}

Layout and Management of Distribution Center is a logistics curriculum with various practical applications. Before the reform, this curriculum was mainly taught following the teachers' program, a task or corresponding exercises, and group discussions by students. Cases and tasks are independent, and tasks have an inadequate driving force. Thus, different modules lack uniformity and immersion. As such, the following design principles were determined to implement gamifying teaching and experiencing teaching.

Game-driven principle. The overall curriculum design follows the principles of uniformity and continuity. The designed teaching program and organization modes aim to stimulate students' curiosity and thirst for knowledge and are driven by games to let students "experience in games, reflect in experiences and understand in reflections" (Fig. 1).

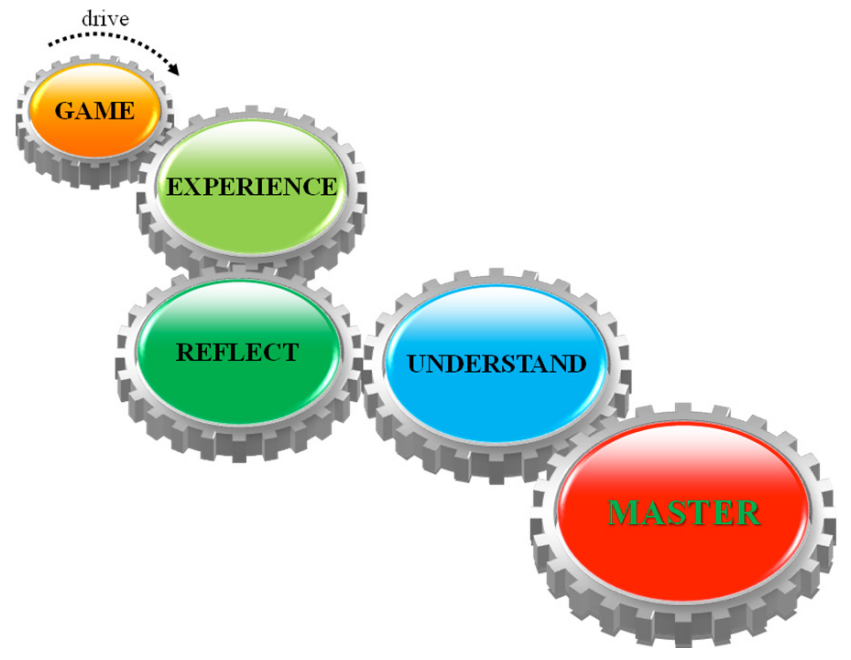

Fig. 1. Game-driven model 
Systematization. The curriculum design of Layout and Management of Distribution Center is organized according to preliminary cognition, processing procedure, inventory prediction, warehouse layout, and overall operations, which agree with the cognitive logic of students. A study on the layout of distribution centers is the final teaching objective, and early teaching contents are centered on this objective.

Learning requires the construction of the overall cognition on the subject that is being studied. A basic introduction to the curriculum was presented through recruitment talks rather than the traditional teaching mode. This approach is conducive for students to learn basic knowledge unconsciously and become absorbed in the comprehension of related contents.

In accordance with the experiences of management staff, the organizational structure and processing procedures of the distribution center need to be reviewed before designing the layout. The organizational structure was introduced in the cognition of the distribution center, and no independent training was offered. Subsequently, the key task lies in the cognition of processing procedures in the distribution center and integrating associated operation standards and theoretical supports into the learning process. Special training was arranged with respect to the key contents of the process of filling out documents, planning of storage locations, and distribution route design.

Essential data have to be understood first before designing the warehouse layout. Inventory data and inventory prediction are the contents that students have to master. Therefore, the corresponding inventory prediction method is arranged, and the key is to learn to calculate inventory prediction results by using Excel.

In the warehouse layout, the meso-level layout in the distribution center has to be solved first. Systematic layout planning (SLP) is introduced so that students can design the location relationship of different regions. The calculation method of major regions is proposed to help students identify the regional layout of the distribution center. Next, storage location planning in the micro-level warehouse is discussed. Entry-item-quantity (EIQ) analysis is studied, which is used as the basic reference for storage location planning.

For comprehensive evaluation of early learning effect and transition to the sand table exercise, a comprehensive exercise on the layout of a consumer goods warehouse is designed. Students are then asked to perform the sand table exercise, which can give them unprecedented learning experiences.

Attractiveness. During a lesson on distribution route planning, the teacher gives the students orders from nine distribution sites. Then, the teacher asks the students to locate the clients on the Baidu Map and calculate the distribution route by using Excel according to the time limit and distribution quantity. In this way, students become interested to know whether their distribution schemes are the optimal schemes. Next, teachers introduce the classical algorithm of distribution route planning, that is, the saving algorithm. Such learning with problems can arouse the learning enthusiasm of students significantly.

Immersion. The curriculum philosophy of recruiting is designed in the overall cognitive project. The entire curriculum is viewed as a training process of reserve cadres for a large distribution center. The first class starts with a picture of a recruitment announcement and a recruitment lecture to attract students to the recruitment 
atmosphere . Next, the distribution center is introduced through a recruitment talk, which involves related knowledge points. Students can indirectly understand the basic concepts of distribution centers in such a setting. Notably, some students view the teacher as the real HR supervisor of the enterprise, exhibiting great respect for the teacher and asking about the enterprise after the class.

In addition, ensuring the reality and uniformity of the tasks and the data used in the cases are necessary to maintain high immersion of the students as much as possible. For instance, a detailed case background and big orders are designed in filling out documents and planning the distribution routes. If the field information involved in the order agrees with the real-life situation of enterprises, then the students can feel a sense of practicality in the exercise.

Acceptability. The curriculum design has to arouse critical thinking, ensure moderate difficulty of the case, and simplify cases to give students a sense of achievement in every stage. Following a macroscopic to microscopic trend, the overall layout methods (SLP and from - to chart method of logistics quantity) of major regions in the distribution center were introduced in the layout planning. Next, it introduces a calculation method for regional areas and a microscopic layout method in the warehouse region. This calculation method is known as the storage location planning method (EIQ analysis). Finally, students are asked to accomplish a comprehensive exercise that involves designing the layout of a consumer goods warehouse. Attention should be given to ensure each small project design is acceptable. For instance, the survey data in EIQ analysis covers more than tens of thousands of orders, and some data are non-normalized. In practical teaching, the teacher makes some adjustments to the actual data and controls the number of orders within a thousand. This approach not only ensures the validity and reality of cases but also controls the difficulty of the cases and allows for acceptability by the students.

\subsection{Design of gamifying teaching}

The teaching program of Layout and Management of Distribution Center is shown in Fig. 2. It allocates knowledge points and skill points to four major projects according to the project-based system. These four major projects are further segmented, and each lesson deals with one segmented project. Each segmented project is designed according to the teaching objective. All projects are divided by using project 5 as the background and developed gradually, covering everything from overall cognition to the processing procedure and then to the warehouse layout. The operation practice and the sand table practice are then conducted. The entire teaching program has clear logic and explicit targets, which enables students to concentrate on learning. A discrete event simulation model in another course will help students further deepen their understanding of the distribution center. 


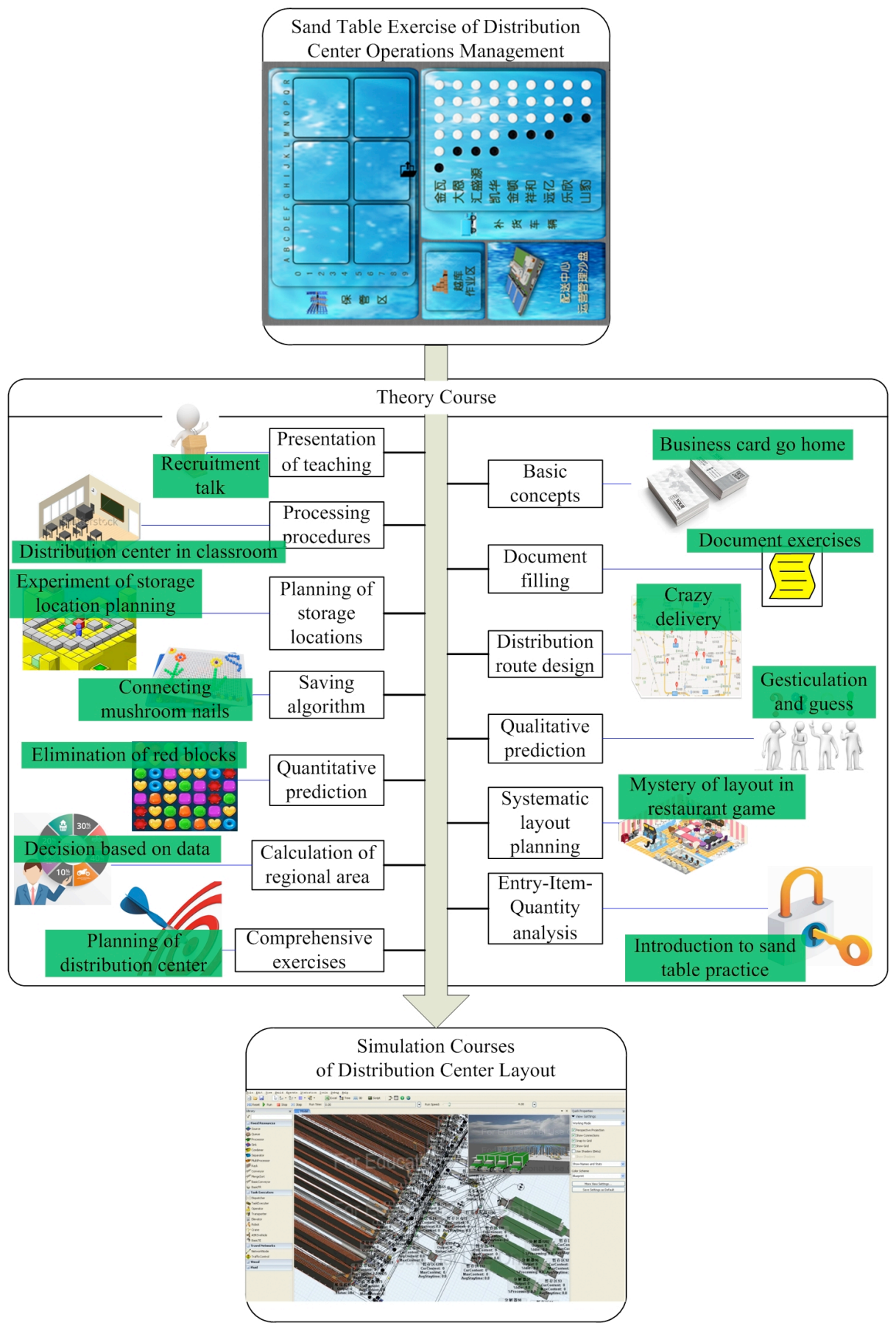

Fig. 2. Gamification design for Layout and Management of Distribution Center 


\subsection{Organization of gamifying teaching}

On the basis of the above teaching design, games are arranged in most projects of Layout and Management of Distribution Center to stimulate the enthusiasm of the students (Fig. 2). These games are illustrated by the following cases.

"Business Card Go Home". The "Business Card Go Home" game is designed in the overall cognition program. In this game, the teacher prepares a business card for each student in advance, distributes them randomly among the class, and asks students to exchange business cards freely from the beginning of the activity up to a certain time limit until each student has his or her own business card. This game allows the students to experience the role of distribution centers through logistics organization.

"Distribution Center in Classroom". The "Distribution Center in Classroom" game is designed in the procedure cognition program. In the past, teachers simply used PowerPoint presentations to introduce the processing procedures of the distribution center, but students find this method boring. Through the game, students can experience and summarize the processing procedures in a distribution center. The teaching design is as follows: first, an order processer, an order picker, a warehouse manager, and a replenishment worker are selected from the students, and the other students roleplay as managers of storage locations. Students simulate the entire processing procedure in the distribution center, including order reception, inventory inquiry, order picking, replenishment, and storage location distribution. This game helps students understand the procedure and the effect of storage location planning on order picking routes and efficiency.

"Crazy Delivery". The "Crazy Delivery" game is designed in the distribution route planning program. Fig. 3 shows that one distribution center and nine distribution sites are chosen according to a certain rule on an online map. Learning groups are asked to deliver commodities from the distribution center to nine distribution sites according to the given orders under certain constraints while maintaining the minimum total cost of distribution.

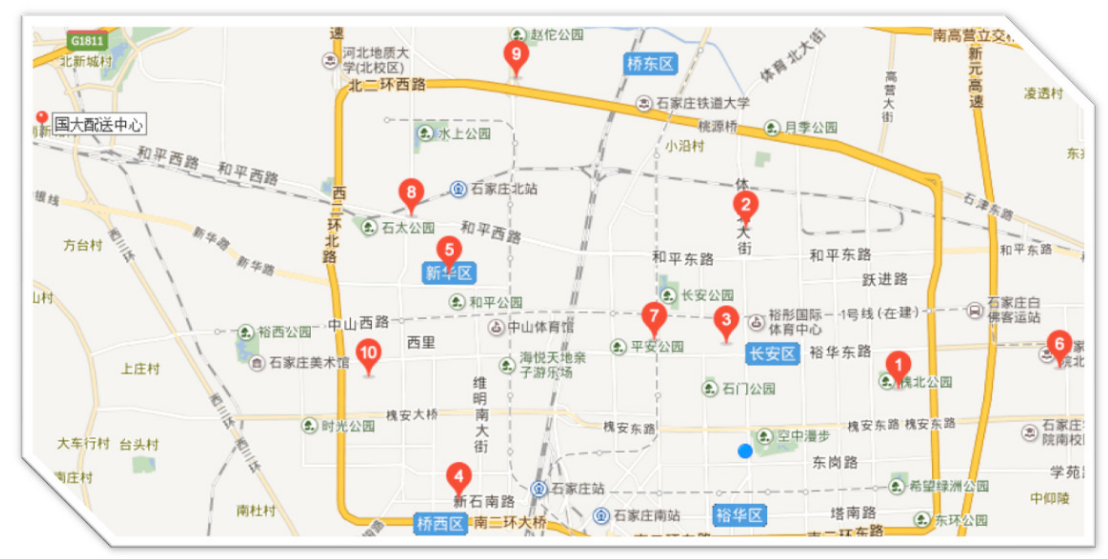

Fig. 3. Reference locations of the distribution center and distribution sites 
"Connecting Mushroom Nails". The "Connecting Mushroom Nails" game is designed in the saving algorithm program. Game props are sent to different groups (Fig. 4). Students have to knock mushroom nails onto a plate according to the teacher's instructions.

The largest mushroom nail stands for the distribution center, and other mushrooms represent the clients. The size of the "client" corresponds to the volume of the delivered commodities, and the color of the "client" reflects the weights of the delivered commodities. Supporting strings that are approximately $20 \mathrm{~cm}$ long (Fig. 5) represent the distribution routes of the vehicles. Study groups buy strings from the teacher and wind them on the mushroom nail that represents the distribution center; the strings should be wound around each "client." Each string has a limited weight and volume of commodities.

This game can guide the students to understand the vehicle routing problem, explore the distribution route planning method, and master the saving algorithm.

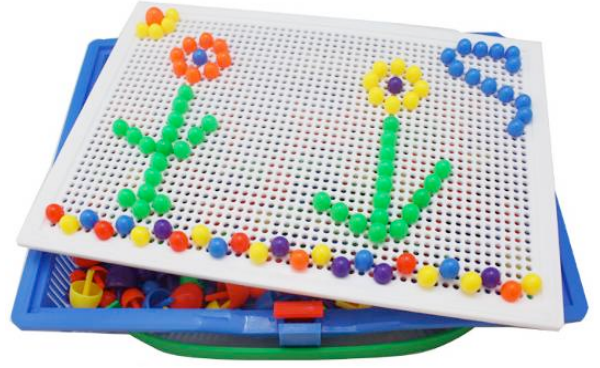

Fig. 4. Game props

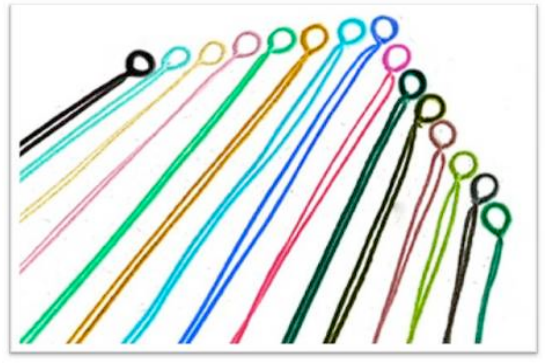

Fig. 5. Supporting strings

Sand Table Exercise of Distribution Center Operations Management. A teacher, who is the first author of this paper, developed the sand table exercise of distribution center operations management in the overall operations program on the basis of his teaching experience and has even applied for a patent (Patent No. ZL201620847300.8). The sand table is shown in Fig. 6. It is the ultimate task of the curriculum and helps students simulate commodity warehousing, distribution of storage locations and order picking route in the distribution center, determination of supply time and quantity, calculation of distribution cost, and optimization of the operation's regional layout. The sand table exercise is shown in Fig.7. The sand table exercise and each program design emphasize the gamification principle, consider both practice and theory, allow students to think during the game, and master the theory related to the problems.

The final evaluation indices of the sand table exercise of distribution center operations management include total profits of different groups $(\pi)$ and the sustainability of the operation state. To ensure the latter, opportunistic practices should be avoided. For example, the sales promotion of commodity $\mathrm{C}$ can save great storage costs in the short run but will bring high shortage costs in the long run. If the inventory of one commodity is lower than its reorder point, then the learning group should reorder this community. However, if they do not reorder at the end of the sand table exercise, then 


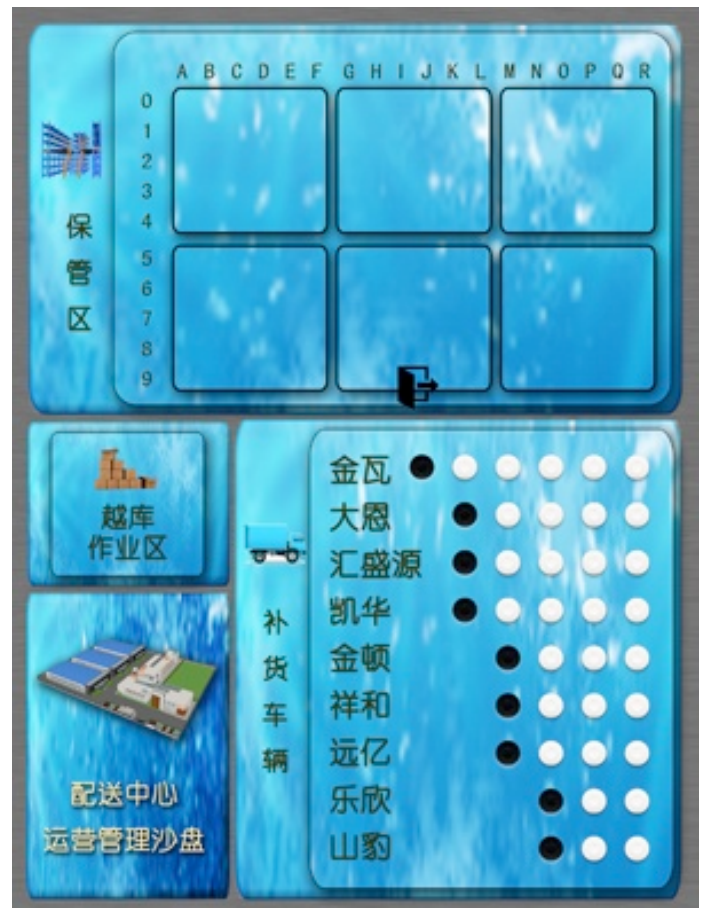

Fig. 6. Sand table surface for distribution center operations management

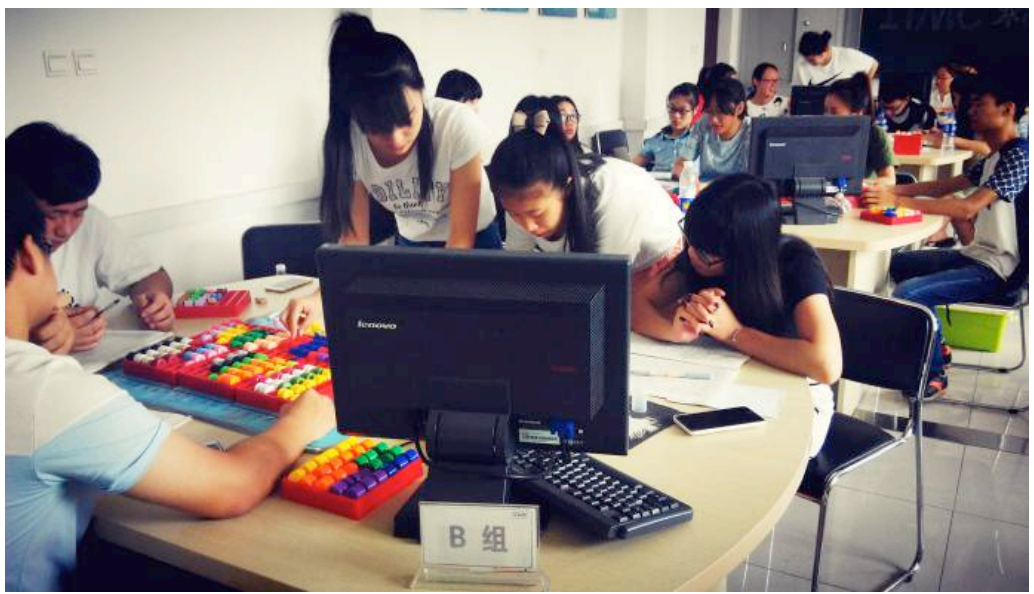

Fig. 7. Sand table exercise

they will not incur shortage costs, thereby resulting in high total profits; this situation is unacceptable. The results are assessed by the teacher at the end of the sand table exercise. Types of commodities, inventory quantity, and quantity of ordered commodities during transportation have to conform to the long-term development demands of the distribution center. 
Total profit $\pi$ is the function of different decision variables

$$
\pi=T R-T C
$$

where $T R$ is the total revenue, and $T C$ is the total cost.

$$
T R=R_{d}+R_{a}
$$

where $R_{d}$ is the distribution revenue, and $R_{a}$ is the additional revenue.

$$
T C=\sum_{i=1}^{7} C_{i}
$$

where $C_{1}$ is the storage cost, $C_{2}$ is the order picking cost, $C_{3}$ is the shortage cost, $C_{4}$ is the order cost, $C_{5}$ is the distribution cost, $C_{6}$ is the cross-docking cost, and $C_{7}$ is the additional cost. The total cost is actually the function of multiple management strategies

$$
T C=F_{1}\left(S_{O}+S_{L}+S_{P 1}+S_{P 2}\right)
$$

where $S_{O}$ is the order strategy, including the reorder point $R O P$ and economic order quantity $E O Q . S_{L}$ is the storage location planning, $S_{P 1}$ is the order picking route planning, and $S_{P 2}$ is the sales promotion strategy of commodities. These management strategies are determined by historical inventory data of the distribution center. For example,

$$
R O P=L T \times D / 360+S
$$

where $L T$ is the purchase period, $D$ is the annual demand for the commodity, and $S$ is the safety inventory.

$$
E O Q=\sqrt{\frac{2 C D}{H}}
$$

where $C$ is the cost of each purchase, $D$ is the annual demand for the commodity, and $H$ is the annual storage cost per unit commodity. While

$$
S_{L}=F_{2}\left(I Q_{1}, I Q_{2}, I Q_{3}, \mathrm{~L}, I Q_{26}, I K_{1}, I K_{2}, I K_{3}, \mathrm{~L}, I K_{26}\right)
$$

where $I Q$ and $I K$ are the delivery quantity and times of different types of commodities, respectively.

$$
S_{P 1}=F_{3}\left(S_{L}, Q_{1}, Q_{2}, \mathrm{~L}, Q_{26}\right)
$$

where $Q$ is the distribution quantity of different types of commodities. 
These factors influence and restrict mutually, thereby making planning the distribution center operations management difficult. Students will have to continuously explore these problems and thereby master the related knowledge points.

\section{$4 \quad$ Results}

The above teaching reform has been applied in Shijiazhuang Posts and Telecommunications Technical College. The curriculum reform team began to accumulate some gamification elements in 2014, implemented the gamification of teaching reform officially in 2015, and continued to improve the teaching program in 2016. The teaching reform achieved good teaching effects. Students are now more active in class and have high expectations for the games of the following classes. Students are highly interested in the sand table exercise and often engage in discussions (Fig. 8).

For a quantitative analysis of the teaching effect before and after the reform, the curriculum reform team investigated the teaching satisfaction with the Layout and Management of Distribution Center. Investigation results are shown in Table 1 and Fig. 9. All evaluation indices increase year by year, thereby indicating the tremendous effect of the gamifying teaching reform.

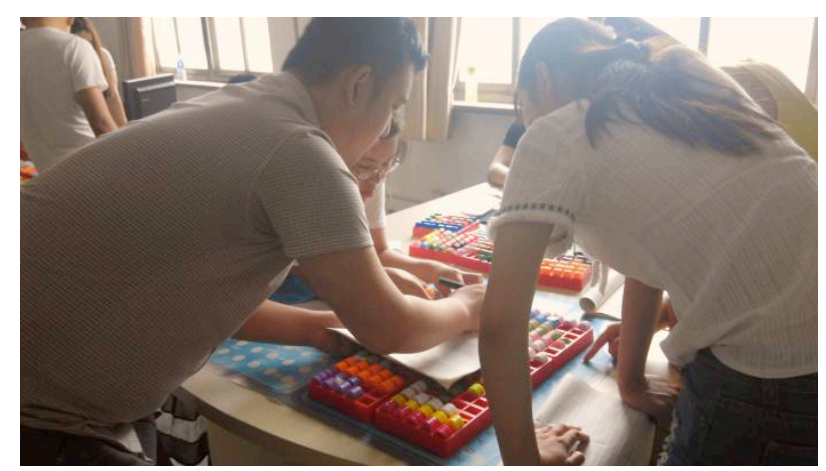

Fig. 8. Positive discussion of exercises

Table 1. Survey data on students' satisfaction in the past three years

\begin{tabular}{|l|c|c|c|}
\hline \multicolumn{1}{|c|}{ Year } & $\mathbf{2 0 1 4}$ & $\mathbf{2 0 1 5}$ & $\mathbf{2 0 1 6}$ \\
\hline Overall evaluation & $89.33 \%$ & $93.80 \%$ & $96.62 \%$ \\
\hline Professional achievement & $89.06 \%$ & $93.33 \%$ & $95.58 \%$ \\
\hline Strong practices & $89.84 \%$ & $92.59 \%$ & $95.58 \%$ \\
\hline Equal communication & $90.79 \%$ & $93.58 \%$ & $95.32 \%$ \\
\hline Teaching organization & $89.52 \%$ & $93.33 \%$ & $96.10 \%$ \\
\hline Explicit goal & $89.21 \%$ & $94.07 \%$ & $95.84 \%$ \\
\hline Teaching idea & $89.84 \%$ & $92.35 \%$ & $96.36 \%$ \\
\hline Classroom effect & $88.57 \%$ & $93.09 \%$ & $96.55 \%$ \\
\hline Teaching interaction & $90.16 \%$ & $92.59 \%$ & $96.10 \%$ \\
\hline Teaching means & $88.25 \%$ & $92.35 \%$ & $96.10 \%$ \\
\hline
\end{tabular}




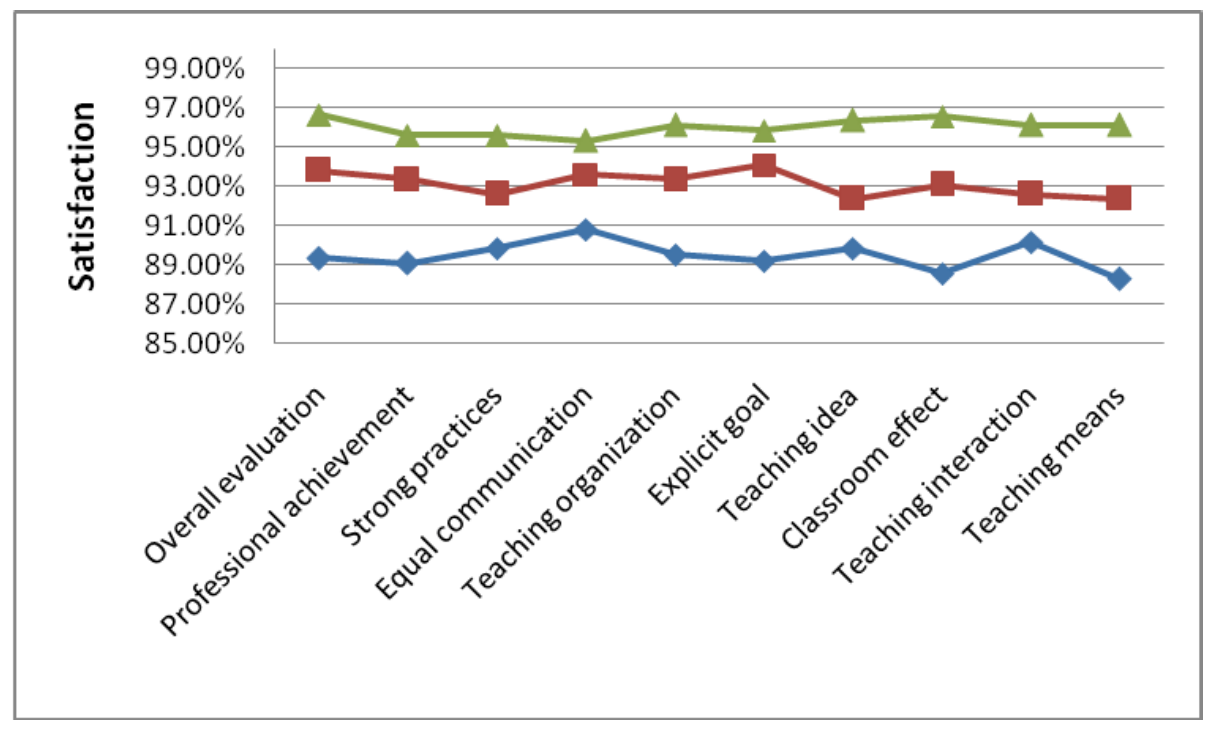

Fig. 9. Satisfaction trend in the past three years

\section{Conclusions}

Reforms to gamify teaching are applied in the Layout and Management of Distribution Center to adjust the curriculum structure and allow the students to accept and even positively explore knowledge through games. On the basis of experiential learning theory and gamification learning theory, the idea and the implementation details of gamifying teaching reform are discussed from the perspectives of curriculum design, teaching organization, and teaching means. The following conclusions are obtained:

1. The overall curriculum design should follow the principle of uniformity and continuity. Teaching design around knowledge points involved in comprehensive exercises is an effective teaching method. Teaching programs based on the same comprehensive exercise can ensure the uniformity of the curriculum. Teaching programs centered on the procedure of the same comprehensive exercise can guarantee the continuity of the curriculum. However, this idea does not mean that the classroom game of each lesson should be continuous. Rather, it can be independent as long as it can reflect specific knowledge points.

2. The teaching design should pay attention to systematization, gamification, and immersion. Systematization requires the teaching design to conform to the cognition law of students and that step-by-step implementation should be applied to ensure that the students understand the learned knowledge. Gamification suggests the integration of game elements into every lesson and allows the students to positively learn in a pleasant atmosphere. Immersion ensures that the cases are realistic and encourages the students to view the simulated classroom environment as reality. 
3. The teaching means should be attractive and acceptable. The attractiveness of the curriculum can be realized by using case studies. The case design needs to agree with the students' interests, introduce students into the knowledge environment, and attempt to solve problems and setbacks. In this way, the theoretical teaching that will follow will be able to naturally attract the students' attention. Acceptability is needed to ensure that the students can understand the teaching content and teachers should pay attention to the reasonably selected teaching content and mode. Different teaching modes such as a micro-course can be adopted to enhance the students' understanding of knowledge.

The curriculum reform team has devoted years to this teaching reform and has achieved outstanding effects, thereby proving that gamifying teaching and experiencing teaching conform to the learning characteristics of modern students and are feasible in higher educational reform.

This study only summarizes specific teaching reform experience. Thus, some experiences have certain limitations and could not be applied to other courses directly. Future research can further extract more universal experiences.

\section{References}

[1] Hanus, M. D., \& Fox, J. Assessing the effects of gamification in the classroom: a longitudinal study on intrinsic motivation, social comparison, satisfaction, effort, and academic performance, Computers \& Education, 2015, vol. 80(80), pp. 152-161. https://doi.org/10.1016/j.compedu.2014.08.019

[2] Attali, Y., \& Arieli-Attali, M. Gamification in assessment: do points affect test performance?, Computers \& Education, 2015, vol. 83(83), pp. 57-63. https://doi.org/10.1016/ j.compedu.2014.12.012

[3] Domínguez, A., Saenz-De-Navarrete, J., De-Marcos, L., Fernández-Sanz, L., Pagés, C., \& Martínez-Herráiz, J. J. Gamifying learning experiences: practical implications and outcomes, Computers \& Education, 2013, vol. 63(63), pp. 380-392. https://doi.org/10.1016/ j.compedu.2012.12.020

[4] Cheong, C., Cheong, F., \& Filippou, J. Quick Quiz: A Gamified Approach for Enhancing Learning, Pacific Asia Conference on Information Systems, 2013, pp.1-14.

[5] Jinlei, Z., \& Baohui, W. Research on applications of gamification learning idea in flipped classroom, Distance Education Journal, 2013, vol. 31(1), pp. 73-78.

[6] Dewey, J. Democracy and education: An introduction to the philosophy of education. New York, U.S.: Macmillan, 1916.

[7] Daniel Conrad, \& Diane Hedin. The impact of experimental education on adolescent development, Child \& Youth Services,1982, vol. 4(3-4), pp. 57-76. https://doi.org/10.1300/ J024v04n03 08

[8] Smith, T. E., Roland, C. C., Havens, M. D., \& Hoyt, J. A. The theory and practice of challenge education. Lowa, U.S.: Kendall/Hunt Publishing Co,1992.

[9] Kolb, D. A. Experiential Learning: Experience As the Source of Learning and Development. ShangHai, China: East China Normal University Press, 2008.

[10] Jinhua, Z., \& Lei, Y. Research review on experiencing teaching, Heilongjiang Researches on Higher Education. 2010, vol. (6), pp. 143-145. 
[11] Deterding, S., Dan, D., Khaled, R., \& Nacke, L. From game design elements to gamefulness: defining "gamification", International Academic Mindtrek Conference: Envisioning Future Media Environments (ACM), 2011, pp. 9-15. https://doi.org/10.1145/2181 037.2181040

[12] Kapp, K. M. The gamification of learning and instruction: game-based methods and strategies for training and education. Beijing, China: China Machine Press, 2015.

[13] Kai, S., Meiyun, Z. \& Dong, K., Is gamifying teaching useful: Comparative analysis of empirical study of education field, E-education Research, 2016, vol. (11), pp. 85-92.

[14] Barata, G., Gama, S., Jorge, J., \& Goncalves, D. Engaging Engineering Students with Gamification, International Conference on Games and Virtual Worlds for Serious Applications(IEEE), 2013, pp.1-8. https://doi.org/10.1109/VS-GAMES.2013.6624228

[15] Nah, F. H., Zeng, Q., Telaprolu, V. R., Ayyappa, A. P., \& Eschenbrenner, B. Gamification of Education: A Review of Literature, International Conference on HCI in Business. Springer International Publishing, 2014,vol. 8527, pp.401-409.

[16] Kapp, K. Gamification: Separating Fact From Fiction, Chief Learning Officer, 2014, vol. 13(3), 45-52.

[17] Xiao, J. Increasing gamification of learning activities of schools: Theory and practice of Mastery Learning of Block, Educational Review, 1987, vol. (2), pp. 72-75.

[18] Steinkuehler, C., \& Squire, K. Videogames and learning. New York, U.S.: Cambridge University Press, 2014. https://doi.org/10.1017/CBO9781139519526.023

\section{$7 \quad$ Authors}

Fan Wang (corresponding author) is a lecturer in the Department of Express Delivery and Logistics, Shijiazhuang Posts and Telecommunications Technical College, Shijiazhuang 050021, Hebei, China (coolbase@163.com).

Yan-Li Wang is a lecturer in the Department of Express Delivery and Logistics, Shijiazhuang Posts and Telecommunications Technical College, Shijiazhuang 050021, Hebei, China (coolbase@163.com).

Xia Hu is an associate professor in the Department of Express Delivery and Logistics, Shijiazhuang Posts and Telecommunications Technical College, Shijiazhuang 050021, Hebei, China (coolbase@163.com). 